\title{
ESPIRAIS CONCENTRADORAS NO TRATAMENTO DE MINÉRIOS DE FERRO: UMA BREVE REVISÃO
}

\author{
Diego de Souza Arenare ${ }^{1}$ \\ Otávia Martins Silva Rodrigues ${ }^{2}$ \\ Armando Corrêa de Araujo ${ }^{3}$ \\ Paulo Roberto de Magalhães Viana ${ }^{4}$
}

\section{Resumo}

A aplicação de espirais concentradoras no processamento de minérios de ferro data da década de 1960 na concentração de hematita especular no Canadá. Desde então, sua aceitação tem sido ampla entre as empresas produtoras de minério de ferro. As espirais, apesar de ter um funcionamento muito simples, possui um dos mais complexos mecanismos de separação entre os métodos gravíticos. Os principais mecanismos de separação descritos na literatura são apresentados neste artigo, assim como as principais variáveis de projeto, as quais também são importantes no que diz respeito a uma melhor eficiência para o processamento de diferentes tipos de minérios, ou diferentes etapas de processo. Por fim, os principais problemas operacionais em circuitos de espirais são apresentados, com algumas sugestões de melhorias.

Palavras-chave: Espiral concentradora; Minério de ferro.

\section{REVISITING SPIRAL CONCENTRATION AS APPLIED TO IRON ORE BENEFICIATION}

\begin{abstract}
The application of spiral concentrators in the processing of iron ores started in the 1960's for the concentration of a specular hematite ore in Canada. Since then, its acceptance has been ample among most iron ore producing companies. Spirals, although presenting very simple operating principles, have one of the most complexes separation mechanisms among all the gravity beneficiation methods. The main separation mechanisms described in literature are presented in this paper, as well as the design variables, that are of fundamental importance with respect to the achievement of a better efficiency for the processing of different types of ores or different stages in the process. The main operational problems occurring in spiral circuits are presented and some suggestions for improvements are made.
\end{abstract}

Key words: Spiral concentrator; Iron ore.

\section{INTRODUÇÃO}

A espiral concentradora foi desenvolvida pelo engenheiro I. B. Humphreys no início da década de 1940, com o objetivo de recuperar ouro associado à pirita. A primeira aplicação industrial foi na concentração de cromita, no estado norte-americano do Oregon, em 1943. Em 1960, pela primeira vez foi empregada na concentração de hematita especular em Quebec, no Canadá, sendo o número de espirais próximo a 2.000 unidades. Somente após a queda da patente, a espiral ganhou maior espaço. Mudanças de vários aspectos foram acrescentadas ao projeto original, aumentando a eficiência e a aplicabilidade do equipamento.
A aplicação em beneficiamento de minério de ferro é comum, principalmente devido aos baixos custos operacionais e em investimentos. Entretanto, o processamento de frações finas $(<0,038 \mathrm{~mm})$ não é possível, tornando outros métodos de concentração mais adequados, como a flotação e a concentração magnética. Este trabalho apresenta os princípios da concentração na espiral, com enfoque para aplicações em minérios de ferro. São discutidos os mecanismos operacionais e de separação, variáveis de projeto e operação de usina.

\footnotetext{
'Engenheiro. Arcelor Mittal. Fazenda do Córrego Fundo, BR38I, Km 522, s/n. Itatiaiucu, MG, Brasil. E-mail: diego.arenare@arcelormittal.com.br ${ }^{2}$ Mestre, Curso de Pós Graduação em Engenharia Metalúrgica e de Minas - UFMG. Rua Espírito Santo, 35, $7^{\circ}$ andar, Centro, Cep 31I60-030, Belo Horizonte, MG, Brasil. E-mail: otaviamartins@yahoo.com.br.

${ }^{3}$ Engenheiro. Research and Development. Mining and Mineral Processing Research Center, Arcelor Mittal. BP 30320, F-57283 Maizières-lès-Metz Cedex France. E-mail: armando.correa@arcelormittal.com.

${ }^{4}$ Professor Adjunto do Departamento de Engenharia de Minas - UFMG. Rua Espírito Santo, 35, $7^{\circ}$ andar, Centro, Cep 31I60-030,

Belo Horizonte, MG. E-mail: pviana@demin.ufmg.br.
} 


\section{PRINCÍPIOS DE SEPARAÇÃO E VARIÁVEIS DE ESPIRAIS CONCENTRADORAS}

A espiral concentradora consiste de uma disposição helicoidal de calhas ao redor de uma coluna central, como mostra a Figura I(a). As principais variáveis geométricas são: ○ passo, a altura, a inclinação e a inclinação radial da calha.

De acordo com Holland-Batt, ${ }^{(3)}$ um fluxo movimentando-se na calha de uma espiral é composto basicamente por dois fluxos: um fluxo primário, no sentido descendente e devido à ação da força gravitacional, e um fluxo secundário, no sentido transversal à calha e devido à ação da força centrífuga. Estes dois vetores produzem uma distribuição das partículas como apresentado na Figura Ib. Podem ser observadas duas zonas principais, separadas por uma zona intermediária.

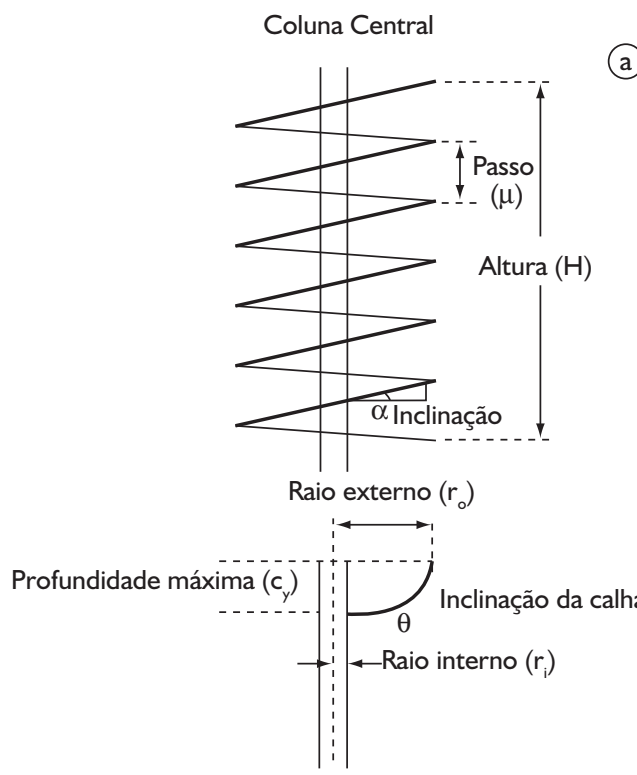

(b)

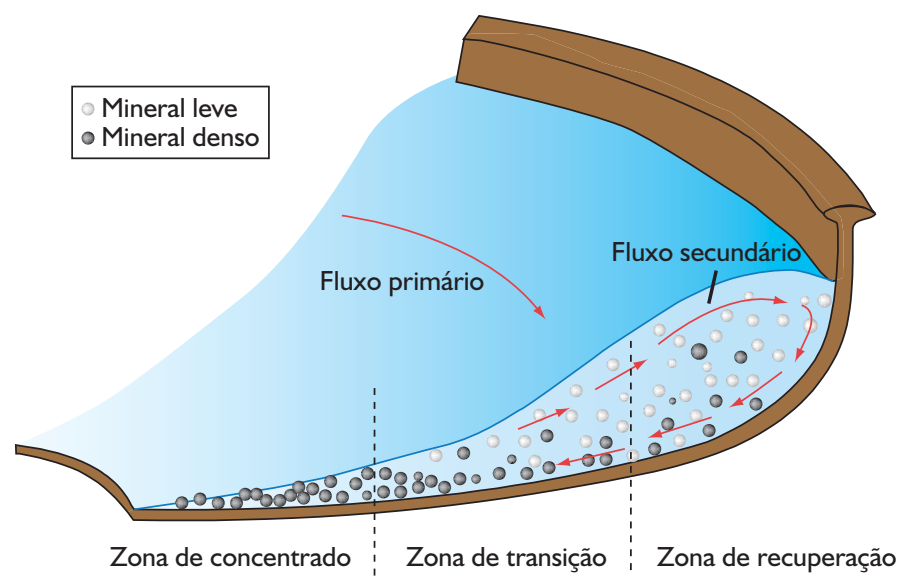

Figura I. a) Parâmetros geométricos de uma espiral concentradora. ${ }^{(1)}$ b) Principais zonas na calha da espiral. ${ }^{(2)}$
Durante a descida da polpa, as partículas densas posicionam-se na zona de concentrado. A separação acontece na zona de transição, onde o fluxo secundário carrega as partículas de menor massa específica para a zona de recuperação, e as partículas densas sedimentam e se dirigem para a zona de concentrado. Como todo método de concentração gravítica, a separação pode ocorrer por massa específica e tamanho. As partículas finas tendem a ser direcionadas para a zona leve, enquanto as partículas grossas tendem à zona de concentrado. Entretanto, partículas muito grossas tendem a ir para zona leve devido à geração de um torque que faz com que elas "colem" através da calha. Partículas próximas à região interior se movem em leito e partículas na região externa se movem em suspensão. Leitos largos podem ocorrer na zona intermediária criando distúrbios no mecanismo de separação. Isso é comum em minérios compostos por minerais de alta massa específica. ${ }^{(4)}$

\section{SEPARAÇÃO HIDRODINÂMICA}

A sujeição das partículas a diferentes formas de fluxo (laminar, intermediário e turbulento) leva à atuação de diferentes forças sobre elas, as quais determinam se seguem para a zona de concentrado ou zona leve. Uma análise quantitativa e detalhada dessas forças é difícil devido ao fato de muitas delas não serem mensuráveis. Cinco forças principais podem ser citadas, ${ }^{(1)}$ sendo que o vetor resultante dessas cinco forças determina a direção da partícula na calha da espiral (Figura 2):

- força da gravidade $\left(F_{g}\right)$ : faz com que as partículas se direcionem à zona de concentrado;

- força centrífuga $\left(F_{c}\right)$ : provoca o movimento radial direcionando as partículas para zona leve;

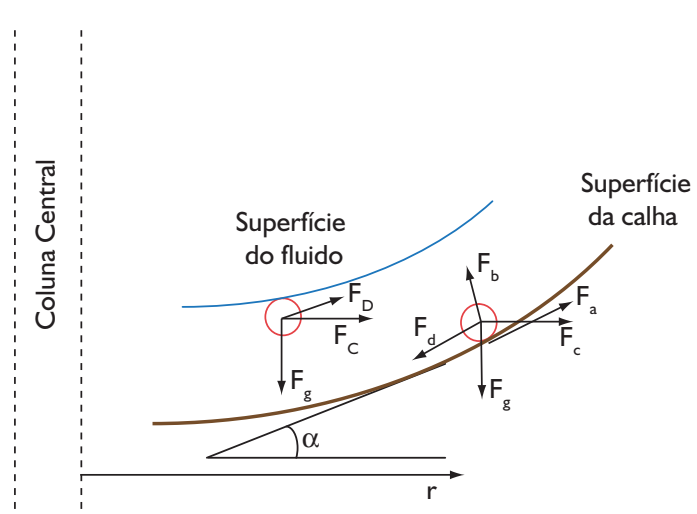

Figura 2. Forças que atuam no movimento das partículas na calha da espiral. 
- força de arraste $\left(F_{D}\right)$ : é a força que o fluido realiza sobre a partícula no sentido do seu movimento devido ao atrito entre o fluido e a superfície da partícula. Para partículas localizadas próximo à superfície livre da polpa, a força de arraste atua no sentido da borda da calha, enquanto em partículas situadas na superfície da calha atua no sentido da coluna central;

- forças de Bagnold $\left(F_{B}\right)$ : atuam no sentido de soerguer as partículas quando estas se encontram próximas à superfície da espiral. Levam à dilatação e ao afrouxamento do leito, proporcionando condições para que ocorra a segregação das partículas segundo o tamanho e a massa específica; e

- força de atrito $\left(\mathrm{F}_{\mathrm{a}}\right)$ : causada pela superfície da calha que se opõe ao movimento das partículas.

\section{VARIÁVEIS OPERACIONAIS}

A taxa de alimentação é a principal variável operacional, determinando a velocidade do fluxo primário e, conseqüentemente, do fluxo secundário. Baixas taxas de alimentação conduzem a uma rápida sedimentação das partículas, levando grande parte delas para a banda de densos. Taxas de alimentação elevadas levam a um aumento da velocidade dos fluxos primário e secundário, levando partículas de finos densos e mistos a serem mantidas em suspensão na zona periférica, além das partículas leves, diminuindo a recuperação, mas aumentando o teor no concentrado. A Figura 3 apresenta os resultados de concentração de minério de ferro para diferentes taxas de alimentação.

A massa específica da polpa desempenha um papel secundário na separação, sendo associada com a vazão. A Figura 4 apresenta resultados, onde são comparadas massa específica da polpa e taxa de alimentação. A recuperação de ferro mostra-se melhor para polpas densas, onde a recuperação é decrescente com o aumento da vazão. O efeito oposto é observado no teor de ferro no concentrado. Comparando com polpas menos densas, polpas de alta massa específica tendem a produzir um concentrado de alto teor.

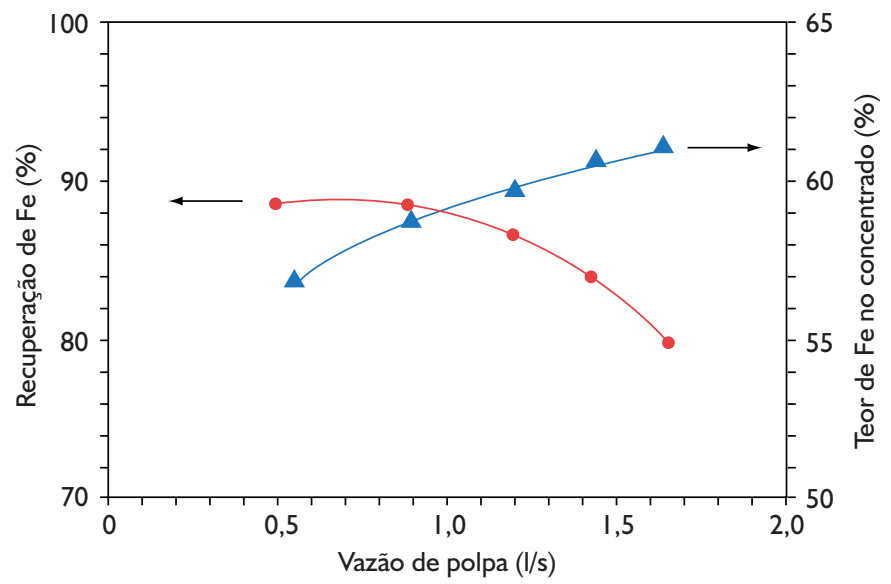

Figura 3. Recuperação versus teor de ferro no concentrado para diferentes fluxos de alimentação. ${ }^{(5)}$
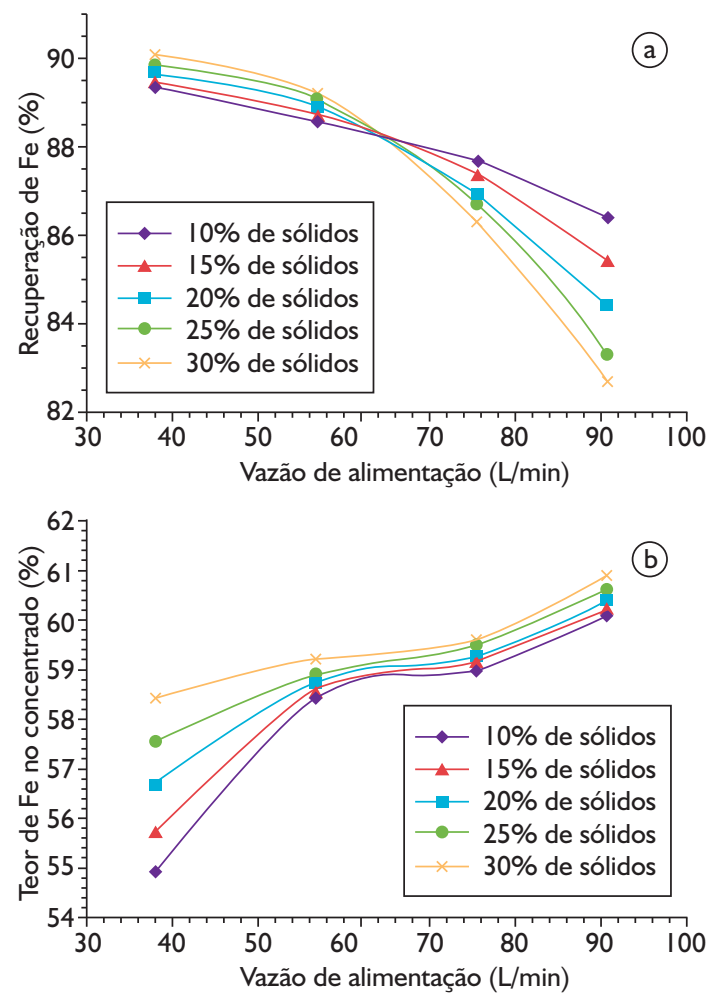

Figura 4. a) Efeito da massa específica da polpa na recuperação; e b) no teor do concentrado. ${ }^{(7)}$

O tamanho das partículas é muito importante no mecanismo de separação da espiral concentradora. Os novos equipamentos são capazes de processar minérios na faixa entre $2 \mathrm{~mm}$ e $0,074 \mathrm{~mm}$. Entretanto, uma faixa muito ampla em tamanho pode maximizar o efeito da separação por tamanho, levando à queda na recuperação, mas sem alterações consideráveis no teor obtido no concentrado. ${ }^{(6)}$

O efeito do teor de ferro na alimentação é estudado por Dallire, Laplante e Elbrond. (7) Como mostrado na Figura 5a, tanto para polpas com $20 \%$ e $32 \%$ de sólidos, o teor no concentrado aumenta para alimentações mais ricas em ferro. Nas curvas de recuperação, apresentadas na Figura 5 b, a polpa a $20 \%$ de sólidos apresenta resultados crescentes com o teor de ferro na alimentação. A polpa a $32 \%$ de sólidos apresenta uma recuperação máxima para alimentações com cerca de $40 \%$ de ferro, com uma queda para alimentações com alto teor. Isso pode ser atribuído à sobrecarga da banda contendo densos, levando estes a serem perdidos no produto leve.

A posição dos desviadores (ou separadores) é uma simples maneira de escolher e especificar a relação teor e recuperação. Quando os desviadores são posicionados perto da coluna central o concentrado produzido tem alto teor e baixa recuperação. 

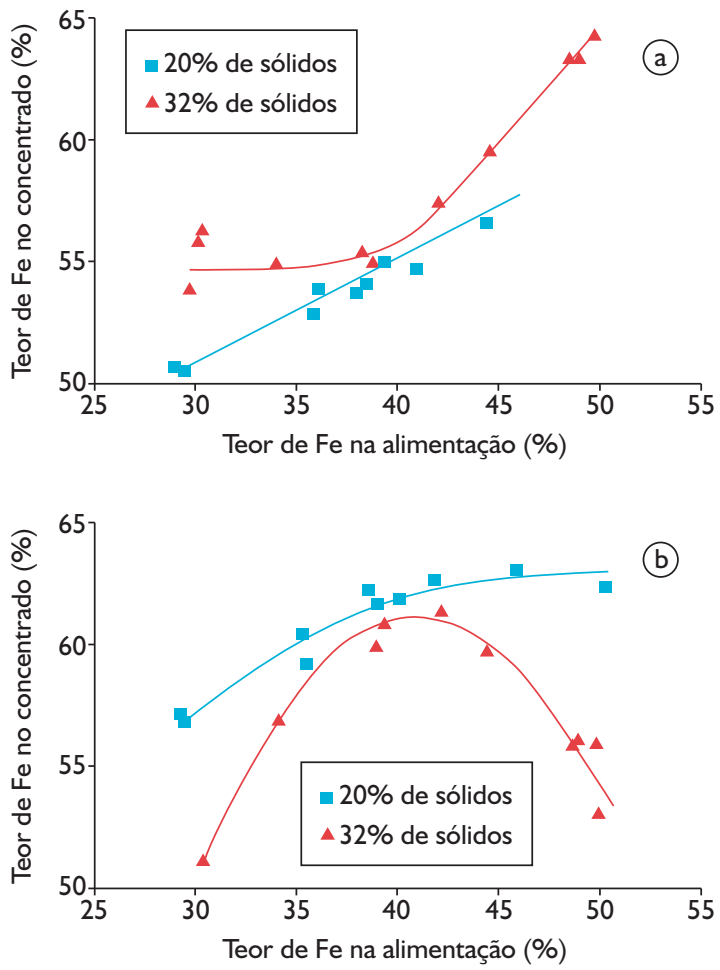

Figura 5. a) Efeito do teor de alimentação no teor de concentrado; e b) recuperação de ferro para diferentes massas específicas de polpa. ${ }^{(7)}$

\section{VARIÁVEIS DE PROJETO}

Seis variáveis principais podem ser listadas com relação ao projeto das espirais: diâmetro da hélice, passo, número de voltas, água de lavagem, posição dos desviadores na calha e sistema de distribuição de alimentação.

O diâmetro da hélice tem influência direta na capacidade de alimentação e na faixa granulométrica. Diâmetros maiores permitem uma melhor separação de materiais com faixas de distribuição granulométrica mais ampla. De maneira geral, o beneficiamento de minério de ferro é feito em espirais com tamanhos de diâmetro intermediários.

O passo determina a velocidade do fluxo primário. Passos maiores possibilitam maiores capacidades porque a velocidade do fluxo é maior. Segundo Wills, ${ }^{(8)}$ o passo influencia na massa específica de separação da espiral, mas não na recuperação e no teor. Massas específicas de separação menores requerem espirais com pequenos passos, enquanto a separação de minerais densos requer espirais com maiores passos. Um exemplo é o sistema hematita e quartzo.

O tipo de operação é determinado principalmente pelo número de voltas. Etapas cleaner são realizadas em menor número de voltas, pois as partículas densas são as primeiras a se sedimentar. Para etapas rougher, é requerido um número maior de voltas, para que as partículas se coloquem na posição de equilíbrio. Entretanto, haverá uma recuperação maior de leves. ${ }^{(8)}$

Quando são utilizadas espirais nas plantas de minério de ferro, os desviadores são usualmente localizados ao longo da calha. Isso normalmente ocorre porque a alta quantidade de minerais densos pode provocar uma sobrecarga na zona interna, o que provocaria alguma ineficiência no mecanismo de separação. Neste caso, requer-se água de lavagem com o objetivo de substituir a água que segue para a zona de concentrado. A quantidade de água perdida é considerável por causa da massa de densos coletada, e se não for reposta haverá perda de eficiência na separação. ${ }^{(9)}$

\section{APLICAÇÕES E PROBLEMAS DE PROJETO NOS CIRCUITOS DE ESPIRAIS}

Embora a espiral não seja um equipamento considerado complicado, uma vez que não possui partes móveis, depois da seleção das variáveis de operação deve-se ter um controle cuidadoso para obter os resultados esperados.

O controle das características da alimentação é muito importante para manter a constância da operação, índices de recuperação e teor do concentrado. As principais variáveis de alimentação que devem ser constantemente controladas são: taxa de alimentação, distribuição granulométrica, teor de ferro e massa específica da polpa. A distribuição granulométrica deve ser estreita. Em algumas plantas, em que a moagem não é aplicada e todo o material é alimentado nas espirais, a perda de partículas grossas no rejeito de partículas leves pode ser considerável. Partículas maiores que $1,2 \mathrm{~mm}$ devem ser separadas após a cominuição por peneiramento, classificação em hidrociclones ou outros equipamentos de concentração densitária.

As lamas contidas também podem ter um efeito negativo no mecanismo de separação, uma vez que elas afetam a viscosidade da polpa. Estas são arrastadas para a zona de partículas leves e causam redução da recuperação subsequente de ferro. ${ }^{(10)}$ Este problema pode ser parcialmente controlado por operações de atrição e deslamagem mais eficientes e um melhor controle da qualidade da água de processo.

Quando as plantas são constituídas por múltiplos bancos de espirais são necessários distribuidores primários. A correta operação para um distribuidor considera a mesma distribuição em relação ao número de saídas em termos de vazão de polpa, porcentagem de sólidos, tonelagem, teor e distribuição de tamanho. Um tubo suficientemente longo deve permitir a estabilidade do fluxo e um perfil simétrico que mantém a homogeneidade da polpa pela seção, evitando segregação da polpa. As linhas de alimentação de cada banco devem ser do mesmo comprimento, quando possível, e mesmas angulações. ${ }^{(I I)}$ 
O controle operacional deve ser eficiente para identificar alguma mudança nas características da polpa. Dispositivos de amostragem instalados em equipamentos podem ajudar a encontrar mudanças. Entretanto, o controle visual por operadores pode dar bons resultados operacionais. Variações nos teores de ferro do ROM podem ser visualizadas se a largura do leito denso mudar. Variações nos teores de sílica também mudarão a cor no leito denso, se a separação não é eficiente. Variações na alimentação ou massa específica da polpa podem afetar a largura do leito denso. Uma melhor massa específica de polpa, associada com um teor de ferro mais alto, pode causar uma sobrecarga no leito denso, criando uma nova zona de corte (em posição diferente da divisão original). Baixas taxas de alimentação levarão menos material pela força centrífuga o que também pode ser visualizado.

\section{OBSERVAÇÕES FINAIS}

A aplicação de espirais na concentração de minério de ferro está em expansão no Brasil e em outros países. As espirais têm apresentado um sucesso especial no processamento da fração fina do sinter feed $(-I+0,15 \mathrm{~mm})$ para produção do sinter feed ou apenas remover ferro desta fração na produção do pellet feed, economizando assim energia na etapa de moagem. A operação deve ser cuidadosa para evitar alimentação de material grosseiro, o que normalmente resulta em entupimento dos desviadores e perda de material grosseiro no rejeito. A máxima que espirais não requerem muita atenção e necessitam de pouca manutenção não expressa a verdade sobre esse maravilhoso equipamento. As espirais requerem atenção e também merecem intervenções de manutenções programadas. Existem algumas plantas de espirais que não produzem os resultados desejados de acordo com o projeto, na maioria dos casos o problema decorre de má operação.

\section{Agradecimentos}

Os autores expressam seus sinceros agradecimentos à Alcoa pelo suporte. Agradecemos também ao Professor Luiz Marcelo Tavares por seus comentários.

\section{REFERÊNCIAS}

I ABELA, R. The effect of slimes content on the rougher spiral circuit in a heavy mineral sands operation. In: HEAVY MINERALS 2003, Johannesburg, South African. Proceedings... Johannesburg: Institute of Mining and Metallurgy, 2003. p. I-7.

2 ABELA, R. Solutions to common design and operating problems in spiral circuits. In: HEAVY MINERALS 2003, Johannesburg, South African. Proceedings... Johannesburg: Institute of Mining and Metallurgy, 2003. p. 9-12.

3 ARENARE, D.S. Estudos de concentração de bauxitas por métodos de concentração gravítica. 2009. 148 p. Dissertação (Mestrado em Engenharia Metalúrgica e de Minas) - Escola de Engenharia da Universidade Federal de Minas Gerais, Belo Horizonte, 2009.

4 ATASOY, Y.; SPOTTISWOOD, D.J. A study of particle separation in a spiral concentrator. Minerals Engineering, v. 8, n. 10, p. II97-208, June 1995.

5 BURT, R.O. Gravity concentration technology. Amsterdam: Elsevier, 1994.

6 DALLIRE, R.; LAPLANTE, A.R.; ELBROND, L. Humphreys Spiral Tolerance to feed variations. Bulletin of Canadian Institute of Mining and Metallurgy, v. 7I, n. 797, p. I23-34, Sept. 1978.

7 DOMENICO, J. The mighty spiral. Outokumpu Technology Physical Separation Newsletter, n. I, p. I-6, Sept. 2005.

8 HOLLAND-BATT, A.B. Some design considerations for spiral separators. Minerals Engineering, v. 8, n. II, p. I38I-I395, Nov. 1995.

9 KAPUR, P.C.; MELOY, T.P. Spirals observed. International Journal of Mineral Processing, v. 53, n. I-2, p.15-28, Feb. 1998.

I0 RICHARDS, R.G.; MACHUNTER, D.M.; GATES, P.J.; PALMER, M.K. Gravity separation of ultra-fine $(-0.1 \mathrm{~mm})$ minerals using spiral separators. Minerals Engineering, v. I3, n. I, p. 65-77, Jan. 2000.

I I WILLS, B.A. Gravimetry concentration In: WILLS, B.A. Mineral processing technology. 5. ed. Oxford: Pergamon, 1992. p. 407-47.

Recebido em: 02/04/2009

Aceito em: 17/06/2009

Proveniente de: INTERNATIONAL SYMPOSIUM ON IRON ORE, 2., 2008, São Luís City, MA. São Paulo: ABM, 2008. 